\title{
First report of Fusarium oxysporum f. sp. radicis-lycopersici in South Africa
}

\author{
A. Jacobs $\cdot$ S. W. van Heerden
}

Received: 17 January 2011 / Accepted: 16 December 2011 / Published online: 20 January 2012

(C) Australasian Plant Pathology Society Inc. 2012

\begin{abstract}
In 2007, vascular browning, root and crown rot were observed on tomato plants in the East London area, South Africa. Fusarium oxysporum f. sp. radicis-lycopersici proved to be a causal agent of the disease by means of morphological and DNA based characterization as well as pathogenicity trials. This is the first report of Fusarium oxysporum f. sp. radicis-lycopersici on tomatoes in South Africa.
\end{abstract}

Keywords Tomato $\cdot$ Fusarium $\cdot$ South Africa

Fusarium oxysporum is an abundant, asexual fungal species complex with numerous morphologically indistinguishable plant pathogenic strains associated with it. Based on the host plant and cultivar specificity $F$. oxysporum strains have been grouped into formae speciales and races, respectively (Armstrong and Armstrong 1981; Di Pietro et al. 2003; Michielse and Rep 2009).

Fusarium oxysporum $f$. sp. radicis-lycopersici causes Fusarium crown and root rot in tomato and is responsible for crop losses in fields and commercial greenhouses (Jones et al. 1991). During their evaluation of the evolutionary relationships between formae speciales associated with tomato Lievens et al. (2009) found multiple evolutionary lineages for both Fusarium oxysporum $f$. sp. radicis-lycopersici and $F$.

\section{A. Jacobs $(\square)$}

Mycology Unit, Biosystematics Division,

Plant Protection Institute, Agricultural Research Council,

Private Bag X134, Queenswood,

Pretoria 0121, South Africa

e-mail: JacobsR@arc.agric.za

S. W. van Heerden

Sakata Vegenetics RSA (Pty) Ltd,

P.O. Box 160, Lanseria 1748, South Africa oxysporum f.sp. lycopersici. The phylogenetic analyses was based on the of the translation elongation factor $1 \alpha$ and exopolygalacturonase genes.

Tomato is an economically important vegetable crop commonly grown by subsistence and resource poor farmers in South Africa. It is one of the main vegetables used for hawking by small-scale entrepreneurs in the informal sector. The total production areas are estimated at more than 5,400 ha. Approximately 100 ha of this area consists of production under protection (tunnels and greenhouses). One of the important regions in terms of hectares under tomato cultivation are the Border area in the Eastern Cape, with 450 ha under cultivation.

Fusarium crown and root rot in tomato has been reported in Japan, Canada, Mexico and the USA (Jones et al. 1991). The disease has not been reported from South Africa, although Fusarium wilt of tomato has been documented (Crous and Baxter 2000). In 2007 symptoms were observed on tomato plants grown hydroponically in the East London area of South Africa which included severe vascular browning, root and crown rot. The aim of this study was to determine the causal agent of Fusarium crown rot in the Eastern Cape area of South Africa.

The infected stems and roots were surfaced sterilized and various sections from infected and clean stem tissue were placed on $1 / 2$ strength Potato Dextrose Agar (PDA), incubated at $25^{\circ} \mathrm{C}$ in the dark for 7 days. Cultures with a typical Fusarium morphology were sub cultured and used for further characterization. Morphological characterisation of the selected isolate (PPRI 9104) was done on a $10 \mathrm{~d}$ old culture grown on Carnation leaf agar (CLA) (Nelson et al. 1983). Morphological characteristics observed were compared with those characteristic of $F$. oxysporum. For molecular analyses the isolate was grown in complete medium broth (CMB) (Correll et al. 1987) at $25^{\circ} \mathrm{C}$ in the dark for $7 \mathrm{~d}$. DNA was 
Fig. 1 Phylogenetic tree of Fusarium oxysporum and related formae speciales produced using parsimony of part of the translation elongation factor $1 \alpha$ gene with $F$. graminearum as outgroup. Bootstrap values above $50 \%$ (percentages of 1000 bootstrap replicates) are indicated in brackets above the branches of the tree. Where space doesn't allow it arrows were added to indicate the branches supported by bootstrap values. Parsimony informative characters $=29$; $\mathrm{CI}=0.965 ; \mathrm{RI}=0.966$; $\mathrm{g}_{1}=-.0743688$. The isolate PPRI 9104 (JQ241434), used in this study, has been deposited in the National Collections of Fungi, PPRI Collection, Plant Protection Research Institute, Agricultural Research Council, Pretoria, South Africa

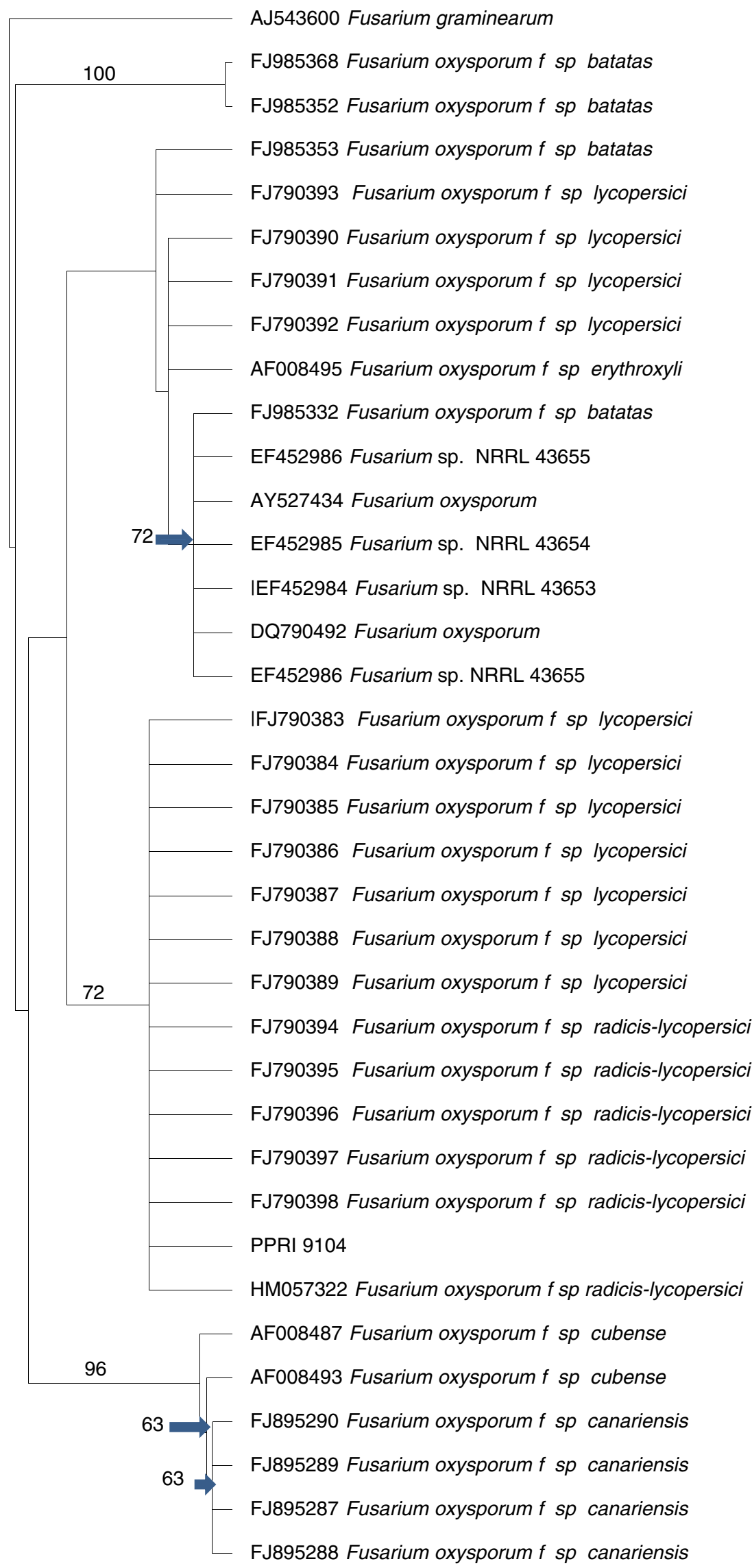


extracted using the DNAeasy Plant Mini extraction kit (Qiagen), following the instructions of the manufacturer. Extracted DNA was used as template in PCR reactions to amplify the partial translation elongation factor- $1 \alpha$ (TEF) gene. Part of the TEF was amplified using the primer set EF1 (5'- CGAATCTTTGAACGCACATTG -3') and EF2 (5'- CCGTGTTTCAAGACGGG -3') (O'Donnell et al. 1998). DNA sequences were determined from $P C R$ amplicons using the ABI PRISM ${ }^{\mathrm{TM}}$ Dye Terminator Cycle Sequencing Ready Reaction Kit with AmpliTaq ${ }^{\circledR}$ DNA Polymerase, (Applied Biosystems, Warrington, UK) using the primers, EF1, EF2. The obtained sequences were compared with sequences deposited on GenBank and the Fusarium Research Centre (Geiser et al. 2004).

DNA sequences were aligned using MAFFT (Katoh and Kuma 2002) by inserting gaps. Gaps were treated as missing data in the subsequent analysis. Phylogenetic analysis was based on parsimony using PAUP 4.0* (Phylogenetic Analysis Using Parsimony* and Other Methods version 4; Swofford 2002). Heuristic searches were done with random addition of sequences (100 replicates), tree bisectionreconnection (TBR) branch swapping, and MULPAR effective and MaxTrees set to auto-increase. Phylogenetic signal in the data sets $(g 1)$ was assessed by evaluating tree length distributions over 100 randomly generated trees (Hillis and Huelsenbeck 1992). The consistency (CI) and retention (RI) indices were determined for the data set. Phylogenetic trees were rooted with $F$. graminearum as monophyletic sister outgroup to the rest of the taxa. Bootstrap analyses were performed to determine branching point confidence intervals (1000 replicates) for the most parsimonious trees generated for the TEF data set.

The purified isolate, PPRI 9104 has been deposited in the National Collections of Fungi, PPRI Collection, Plant Protection Research Institute, Agricultural Research Council, Pretoria, South Africa. This isolate, obtained from the disease material, was used in inoculation trails. Both susceptible and resistant lines of tomato were used as part of the trials. The inoculum for the pathogenicity trials was prepared by transferring mycelial plugs to a $500 \mathrm{ml}$ flask containing $100 \mathrm{ml}$ of Czapek-Dox broth and covered with foil. The broth culture was shaken for 6-7 d on a reciprocal shaker $(150 \mathrm{rpm})$ at $20^{\circ} \mathrm{C}$. Spores were harvested by filtration through cheesecloth and the concentration adjusted to $2 \times 10^{7}$ microconidia $/ \mathrm{ml}$.

For each line, seeds were sown in seedling mix and inoculated when the first true leaf emerged (10-14 d after sowing). Twenty plants were inoculated and 10 served as controls. Inoculations were done by dipping both the roots $\&$ hypocotyls in a beaker with $50 \mathrm{ml}$ inoculum for $3 \mathrm{~min}$ and then planting the seedling in the sterilized medium. Inoculated plants were housed in a phytotron at $20^{\circ} \mathrm{C}$ with $10 / 14 \mathrm{~h}$ light/dark cycle. Disease symptoms were evaluated based on the host reaction 10 d.a.i using the controls and uninoculated plants as reference. The pathogen was re-isolated from the diseased material as a pure culture and preserved. The following disease severity index was used in rating the plants. $0=$ healthy roots, $1=$ minute root lesions, slightly discoloured cotyledon and isolated points of discoloration, $2=$ Small root lesion, chlorotic cotelydon with slight discoloration, $3=$ Extensice root rot, wilting colelydon and part of true leaves, stunting and severe discoloration, $4=$ Collapse of root system, wilting or death to prove Koch's postulates.

The selected isolate was examined and its identity was confirmed to be Fusarium oxysporum, based on morphological characters such as the presence of chlamydospores, macro and micro conidia morphology and colony colour. The partial sequence data for the translation elongation factor1- $\alpha$ was compared against both the NCBI (GenBank) database and the Fusarium Database (Geiser et al. 2004). In both these independent analyses the isolate (JQ241434) matched both $F$. oxysporum f. sp. radicis-lycopersici and F. oxysporum f. sp. lycopersici, (AF008510 and DQ016284) with e-values of zero, indicating a $99 \%$ similarity, but the score-values for $F$. oxysporum f. sp. radicis-lycopersici and F. oxysporum f. sp. lycopersici, were, 1158 and 1151, respectively, indicating a better fit of the data, than that for $F$. oxysporum f. sp. lycopersici. A phylogenetic analysis of the partial TEF gene data clustered the unknown isolate together with the above mentioned species, into the same clade, with no resolution within the clade (Fig. 1).

One week after inoculation, crown rot appeared at the crown area in the form of dark-brown lesions. Subsequently, the lesion enlarged and girdled the entire crown. Two to three weeks after inoculation, the plants wilted and the roots were rotten. Plants with damaged roots were rated as susceptible.

The diseaese severity scale was used to indicate the level of symptom development in the selected tomato and the causal agent was re-isolated from the inoculated material. This is the first report of Fusarium oxysporum f. sp. radicislycopersici on tomatoes in South Africa.

\section{References}

Armstrong GM, Armstrong JK (1981) In: Nelson PE, Toussoun TA, Cook RJ (eds) Fusarium. Disease,Biology, and Taxonomy. State University Press, University Park, pp 391-399

Correll JC, Klittich CJR, Leslie JF (1987) Nitrate nonutilizing mutants of Fusarium oxysporum and their use in vegetative compatibility tests. Phytopathology 77:1640-1646

Crous PW, Baxter A (2000) Plant pathogenic fungi of South Africa. APS Press

Di Pietro A, Madrid MP, Caracuel Z, Delgado-Jarana J, Roncero MIG (2003) Fusarium oxysporum: exploring the molecular arsenal of a vascular wilt fungus. Mol Plant Pathol 4:315-326 
Geiser DM, Jimenez-Gasco MM, Kang S, Makalowska I, Veeraraghavan N, Ward TJ, Zhang N, Kuldau GA, O’Donnell K (2004) FUSARIUM-ID v. 1.0: A DNA sequence database for identifying Fusarium. Eur J Plant Pathol 110:473-479

Hillis DM, Huelsenbeck JP (1992) Signal, noise, and reliability in molecular phylogenetic analyses. J Hered 83:189-95

Jones JB, Jones JP, Stall RE, Zitter TA (1991) Compendium of tomato diseases. APS Press.

Katoh M, Kuma M (2002) MAFFT: a novel method for rapid multiple sequence alignment based on fast Fourier transform. Nucleic Acids Res 30:3059-3066

Lievens B, van Baarlen P, Verreth C, van Kerckhove S, Rep M, Thomma BPHJ (2009) Evolutionary relationships between Fusarium oxysporum f. sp. lycopersici and $F$. oxysporum $\mathrm{f}$. sp. radicis-lycopersici isolates inferred from mating type, elongation factor-1alpha and exopolygalacturonase sequences. Mycol Res 113:1181-1191

Michielse CB, Rep M (2009) Pathogen profile update: Fusarium oxysporum. Mol Plant Pathol 10:311-324

Nelson PE, Tousson TA, Marasas WFO (1983) Fusarium Species: an illustrated manual for identification. Pennsylvania State University Press, University Park

O’Donnell K, Kistler HC, Cigelnik E, Ploetz RC (1998) Multiple evolutionary origins of the fungus causing Panama disease of banana: Concordant evidence from nuclear and mitochondrial gene genealogies. Proc Natl Acad Sci USA 95:2044-2049

Swofford DL (2002) PAUP*: Phylogenetic analysis using parsimony (*and other methods). Sinauer Associates, Sunderland, Massachusetts 